\title{
Rationality and belief in learning mathematics
}

\author{
Tony Brown ${ }^{1}$
}

Published online: 16 December 2015

(C) Springer Science+Business Media Dordrecht 2015

\begin{abstract}
This paper argues that rationality and belief are mutually formative dimensions of school mathematics, where each term is more politically embedded than often depicted in the field of mathematics education research. School mathematics then presents not so much rational mathematical thought distorted by irrational beliefs but rather a particular mode of activity referenced to the performance of certain substitute skills and procedures that have come to represent mathematics in the school context as a result of social management. The paper considers alternative modes of apprehending mathematical objects. Firstly, two accounts of how a young child might learn to point at mathematical entities are presented, where alternative interpretations of this act of pointing are linked to conceptions of enculturation. This comparison then underpins a discussion of how mathematics is produced as entities to be acquired according to certain ideological schema. The resulting cartographic definition of mathematics steers the production then selection of learners according to arbitrary curriculum or assessment criteria. Secondly, some trainee teachers report on shared experience in a spatial awareness exercise concerned with exploring alternative apprehensions of geometric objects. This provides an account of my own teaching and explains why I find teaching mathematics so exciting if it can be linked to the generation of multiple perspectives. The paper's central argument is that rational mathematical thought necessarily rests on beliefs set within a play of ideological framings that within school often partition people in terms of their proxy interface with mathematics. The challenge is to loosen this administrative grip to allow both students and teachers to release their own powers to generate diversity in their mathematical insights rather than conformity.
\end{abstract}

Keywords Rationality·Belief $\cdot$ Ideology $\cdot$ Learning mathematics

Tony Brown

a.m.brown@mmu.ac.uk

1 Education and Social Research Institute, Manchester Metropolitan University, 53 Bonsall Street, Manchester M15 6GX, UK 


\section{Introduction}

The supposed wonder of mathematics is often lost in schools as a result of teachers being accountable to examination regimes that have been created ostensibly in support of the mechanical processes that govern our lives. Pedagogical mediations have a tendency to shape mathematical ideas so that they can be more readily seen, tested or applied. Even university mathematics comprises particular topographies anchored on selected objects or procedures prevalent in certain places at particular points in time. Meanwhile, various styles of mathematical thinking have been created, selected or funded to support practical enterprises such as building bridges, the effective analysis of economic models and everyday finance. The relevance of these enterprises, however, ebbs and flow as time goes by, and so do the forms of mathematics that are produced in support.

The realisation of this contingency troubles any account of mathematics existing out there waiting to be discovered or being seen through the objects that have already been noticed. It frustrates any attempts to pinpoint the undeniable successes of mathematical thought through its visible effects in everyday practical activity. Yet, it is commonly thought that there is something significant in mathematical thought itself that needs to be accounted for beyond its everyday appearances in the physical world. Seemingly, such thought has properties and a precision that produces results unlike other symbolic frameworks. Our practical applications, however, cannot fix our mathematics thinking forever. Its empirical link to seemingly tangible objects ultimately slips away.

This paper seeks to show how its supposed existence beyond its appearances relies on a play of ideological perspectives and the learner's understanding of the demands that they face. The cut between those included in and those excluded from mathematical activity has nothing to do with any supposed intrinsic qualities of mathematics but everything to do with how mathematical ideas are packaged for human consumption. The paper argues for a more liberal attitude to the production of mathematical insights.

The paper begins by considering the production of mathematics as a cultural practice and the apparent social division of labour between those who do more advanced mathematics and those who have it done for them. It ponders on the impossibilities of precisely locating mathematical entities, caught as they are between alternative social constructions. Section 2 focuses on the apprehension of mathematical objects by examining how we might conceptualise both a person pointing at an object and the apprehended object itself amidst diverse contextual parameters. Section 3 shows how the ideological space of schooling frames mathematical objects to suggest a field of mathematics that transcends its Everyday manifestations. An example is then provided of student teachers encapsulating their perceptions during a spatial awareness exercise. The diversity of responses reveals alternative subjective positions each highlighting different qualities of the apprehended object. The paper concludes by arguing that mathematics is built into the human self-image clouding from view the earlier human construction of, or belief, in that mathematics. That is the rationalities of mathematics are always being re-constructed anew by each generation according to their beliefs, ideological preferences, or specific "societal mediation" (Roth, 2012). but where those attributes slip beneath one's own selfconsciousness and disturb its capacity to be complete. The paper argues for a loosening of administrative arrangements that restrict the options available to learners of mathematics in schools. 


\section{The location of mathematics}

This section discusses how one acquires mathematical understanding and where and when it comes into being. We often trust in a mathematics that appears to exceed us and perhaps everyone else. As a mathematically adept reviewer of this paper put it: "I believe the fourcolour theorem has been proved, even though I have neither the know-how, inclination, or time to verify the proof". Probably, all people prefer to let others know or do mathematics for them to some degree. Slavoj Žižek, however, who has been a major influence for this paper, provides a rather sceptical view of Stephen Hawking's success in speaking for mathematics and physics to a wider public. Žižek (2001, p. 213) sees Hawking as a "new type of public intellectual ... who, in the eyes of the wider public, stands more and more for the one 'supposed to know', trusted to reveal the keys to the great secrets which concern us all." A division is created between those who know and those who feel they no longer need to as they defer to experts or machines.

Clearly, no single person could know the full extent of mathematical knowledge. Yet for many people in the wider population, this trust in other people, or in technology, to do their mathematical thinking for them is rather more fulsome. Only half of British adults seem to achieve the level of an average 11 year old, and very often members of the other half expressed their emotional attachment to mathematics through pride in their deficiency (Paton, 2012). This disinclination to participate has provoked widespread curriculum reform targeted at ensuring that enough of the populace achieves some sort of basic functionality in the subject. These strategies sometimes fall short of providing the beauties of abstract thought and can shape mathematical thinking according to a consumerist agenda in which the learning of mathematics is seen primarily as the acquisition of knowledge specified in pre-defined ways.

I concur with Pais (2015) who has argued that this polarisation of attitudes to mathematics is structural and endemic to the capitalist contextualisation of our practice. It is a matter to be lived with rather than resolved through supposing that differences between people can be reduced. That is the social structure shapes mathematical thinking according to current societal norms, defining human identifications with mathematics according to the divisions of labour endemic to the structure. For example, word problems are never innocent. They typically depict a Western rectilinear world described according to specific practices, discursive genres, demographic makeup and economic priorities. This paper is essentially arguing that it is not possible to see mathematics outside of its apparent manifestation in such structures, but that school imposes further restrictions. The paper also presupposes that it is also impossible for each of us to see ourselves outside of those structures. $^{2}$ Our reality (e.g., capitalism) always already includes us as part of it.

Is then the mathematics that Hawking generates in his mind? Or is it in his gesturing finger movement that activates his computer? Or is the mathematics in the computer? Does

\footnotetext{
${ }^{1}$ Žižek's work is influenced by the psychoanalytic theory of Lacan. This sort of "displacement of our most intimate feelings and attitudes onto some figure of the Other is at the very core of Lacan's notion of the big Other; it can affect not only feelings but also beliefs and knowledge - the Other can also believe and know for me" (Žižek, 2006, p. 27).

${ }^{2}$ These Symbolic (rational) structures that shape our ideological space are within a knot of mutually dependency with our Imaginary (beliefs) of who we are, and the Real that defies all symbolisation. As Lacan (2000, p. 95) puts it: "The aggressive tension of this either me or the other is entirely integrated into every kind of imaginary functioning in man". Brown (2011) has explicitly discussed this play of perspectives in the context of mathematical learning.
} 
mathematics rely for its existence on the computer's output impacting on the interpretations of the community of mathematicians? Let us try to unfold the backdrop to these questions. Perhaps in Hawking's case, mathematics and physics live through their dissemination in best-selling populist texts. In part, the existence of mathematics is underwritten by its materialisation in structures, processes and human action, as things that can be pointed at. For example, extensive work on gesture within mathematics education research has considered how mathematical entities are materialised in human activity. De Freitas and Sinclair $(2012,2014)$ explored the alternative productivities of gestural and diagrammatic evocations of mathematical ideas. They asked how the qualitative dimensions of mathematics were a function of such materialisations. That is, is mathematics the same when it is pointed to in a gesture as when it is encapsulated in a diagram? How do they differentially evoke mathematical objects and the (human) subjects creating them? We cannot readily draw a clear line between the human body and their operation of cultural machinery (Barad, 2007). As a learner of mathematics, my sense of where mathematics is located is never finally resolved. Is it part of me or not? Have I made it? Have I pointed to it? Or, to use my country's colloquial educational parlance, has it been delivered to me as if it is a product brought to me by a supermarket van? These concerns prevent any final resolution of the issue of location. Mathematical ideas necessarily comprise a play of perspectives.

\section{What is the point?}

How then might mathematics relate to the "real" world? To what extent can mathematics be referenced to ostensible objects? How is it possible for someone to point at those objects? Let us take an example arising from a discussion between some delegates at the 2013 conference of Mathematics Education and Contemporary Theory. Julian Williams presented a critical analysis of a book by Wolff-Michael Roth and Luis Radford (Roth \& Radford, 2011). The specific concern related to how the teacher and student identify and share a mathematical object. Williams (2015) provided two alternative accounts of how a child learns to point at an object, and by implication, two alternative accounts of how an object is brought into being. He attributes the first to Roth and Radford. He argues that the second is more in line with Vygotsky.

\section{Account one: an infant makes a random gesture}

an infant makes a random gesture that seems to the carer/parent as though the infant might be pointing, the carer/parent interpret it as pointing, and consequently reach out and give the infant the object pointed to, and thereby 'teach' the infant to point at desired objects. (Williams, 2015)

Williams cites Roth et al. (2011, p. 69) on this point:

A movement receives the sense of an action of a particular kind first by the culturally competent individual before this sense comes to be actualised by the child. In the example Vygotsky provides, there first is a random movement. The child does not know 
its cultural signification; it does not (yet) know to point. Rather the parent who sees the child move understands it as a pointing gesture.

\section{Account two: the infant has a clear purpose in reaching out}

the infant initiates the joint activity by having a clear purpose in reaching out to grasp some desired object, such as a dummy or shiny toy. It is this desire which is interpreted by a culturally competent carer/helper, one who empathises with the infant's frustration, and who is thus motivated to help the infant relieve their frustration by progressing the action towards fulfilling its goal. The infant has then to notice the carer's action, recognise its association with their grasping movement, and practice this on a number of occasions. The practised infant looks at a desired object, reaches out, 'points', and looks to the carer for their reaction. The evolution of 'reaching out to grasp' into 'pointing to indicate' as a means to grasp/act on an object-motive and achieve a desired outcome involves an internalisation of pointing as a communicative act, whereupon the child has 'learnt to point'. (Williams, 2015)

In both accounts, the pointing relation involves an algebraic connection between a signifier and a signified. This hand position is associated with that object. I recall a seminar led by Caleb Gattegno where he made this point in mentioning the example of a baby pointing to a fly moving on the ceiling. But which came first, the pointing hand or the object? In the case of a shiny toy, a dummy or a fly, the hand points at a pre-existing entity. An alternative however is for the pointing hand itself to bring the object into existence. The discussion gets more complicated if attention turns to how the teacher and student might point at an algebraic relationship as an algebraic relationship. There are many ways of understanding teachers and students, and the subjective positions that could be assumed by them. There are also many ways of understanding algebraic relationships. That is, the symbolic objects of algebra can be framed (or cut) in different ways according to the subjective position being assumed in relation to them. In the teaching relationship that Roth and Radford are depicting, the teacher is pointing at an algebraic relationship as a teacher, where the "object-motive" is for the student to see this algebraic relationship.

There are however some issues that prevent us from framing or evaluating this encounter in a definitive way. Williams raises the question as to whether the student is required to see the object in the same way as the teacher, or if the object is transformed through the pedagogical encounter. Williams favours the latter, and further, where the object-motive is encapsulated within a particular curriculum structure that fixes pedagogical relationships according to some particular ideology of education. For instance, the current obsession with international comparisons shapes curriculums so that algebraic relationships are framed according to how they would be tested within that regime. That is, the ideological productivity of the pedagogical encounter affects the object in question by situating it within a context or frame that favours some interests rather than others.

A more radical alternative might question the wider framing that promotes and situates algebraic relationships as having a pivotal role. As Williams suggests, Roth and Radford's discussion is centred on the apparent expression of emotion by some very specific sorts of students in a laboratory classroom governed by a school structure that shapes the teachers, students and mathematics within it. There are other ways of doing it. Local administrations 
variously shape mathematical instruction to facilitate learning in particular settings where maybe: children are taught differently according to their ability, customary choices prevail (class size, resource allocation, styles of teaching), mathematical teaching is differentiated according to social group, the resistance of adolescents to adult guidance results in teaching styles being shaped by the needs of classroom management, etc. More generally, teacher capabilities are dependent on a broad range of factors. For example, generalist teachers at primary level may be insecure or unknowledgeable about algebraic relationships. This could affect how students encounter algebraic relationships, perhaps through didactic approaches with reduced scope for exploration or through a published teaching scheme in which the teacher herself has a rather marginal pedagogical role. More widely, setting policy to bring about widespread adjustment to teacher practices towards raising "standards", or national test scores, is a persistent aspiration. Yet, advisory groups, regulators, trainers, research funding agencies and potential employers work according to a variety of perspectives and priorities in terms of what a curriculum is intended to achieve. This variety of interest results in disjunctions between specifications of policy, implementation by teachers and the conceptualisations made of such implementations by researchers across many diverse studies. In short, the constitutions of teachers, students and mathematics are contingent on many factors. The act of pointing at an object can never be understood in a straightforward manner as both pointer and pointed at defy sustainable encapsulations.

\section{Curriculum as acquisition}

School mathematics is understood through curriculum formulations, teaching schemes and textbooks that challenge children and teachers to follow or create mathematical procedures. These formulations are shaped around objects that could be pointed at and become more or less familiar objects through repeated use (e.g., circles, fractions, Pythagoras formula) or procedures (e.g., long multiplication, factorising). Particular styles of questioning are favoured, especially those that more readily lead to clearer assessment and specific modes of interpreting pedagogical encounters. These familiar mathematical forms have become the institutionalised markers of much school mathematics that promote conformity (Brown \& Clarke, 2013; Brown \& McNamara, 2011; Williams, 2015). For example, multiplication tables often provide a key reference point in school mathematical learning and become part of the caricature of mathematics with which pupils identify. That is, they develop a view of "multiplication tables" as being a key part of mathematics and begin to understand themselves as being mathematical through indicators, such as their proficiency in learning their tables.

The literature in mathematics education research has widely reported on the caricatures or beliefs, which orient the pupils', or teachers', broader mathematical understanding, shape their experience of the "pedagogical encounters" that bring them together and, less often, of the notional "macro political context" that shapes their actions. Fishbein (1987, p. 206) argued "there is a world of stabilized expectations and beliefs which deeply influence the reception and the use of mathematical and scientific knowledge". Yet, Leder, Pehkonen and Törner (2002, p. 1) saw this dimension as a "hidden variable in mathematics education”. Goldin, Rösken, and Törner (2009) have reviewed the large volume of later work that has addressed this apparent deficit. Skott (2014, p. 3) has more recently suggested that research could usefully "shift the focus from beliefs to the pre-reified processes that are said to give rise to them". For instance, our beliefs with regard to 
school mathematics relate to rationalities, cartographies and codes of conduct produced through earlier beliefs. More broadly, the addition of elements to the school curriculum (e.g., tables and graphs) and the reduction of other areas (e.g., geometry) mark the ongoing historical formation of mathematical ideas in the context of social practices. Systems of rationality evolve with beliefs: "what others have learned has to be re-learned, reintegrated and re-expressed in each generation" (Mason, 1994, p. 177). "the being of what we are is first of all an inheritance, whether we know it or like it or not" (Derrida, 1994, p. 54). Ernest (2015) discusses this matter in detail through historically changing understandings of certainty in mathematics.

For example, school mathematical themes could be seen as being constituted through counting as one a certain set of objects (tables, graphs, etc.) (Brown, 2011). But similarly, the points on the curve produced by the equation $y=x^{2}+3$ get counted as one and get to be called a "quadratic" so that the term "quadratic" becomes a particular enshrined object within the landscape in question that anchors or guides how we make sense (Brown, Heywood, Solomon, \& Zagorianakos, 2013). Yet, the statements that seek to locate and define mathematical phenomena so often become the statements that police its boundaries and set its policies on inclusion and selection. Pupils must know their tables and recognise a quadratic if they are to advance in their mathematical studies in school, as it is understood within the particular regime.

Further, mathematics, as it is taught in many schools, is often referenced to the sort a university academic mathematician would suppose to be a mathematical content. This may provide the frame of reference against which the correctness of mathematics carried out by children in schools is judged. The mathematics encountered in schools is also locally defined around social practices, such as calculating supermarket bills, estimating the number of bricks needed for a wall and predicting demographic trends. The point, however, is not to target the supposed underlying mathematics as the ultimate quest but rather to (1) question why mathematical activities in the classroom have assumed the social forms that they have and (2) to explore the consequences of those outcomes. The English mathematics curriculum has partitioned mathematical ideas and themes for consumption in schools. The British government has exercised its control over teachers and students by specifying specific skills and competencies, which stand in for the government's supposed obligation to promote a numerate population with consequent benefits to our society, technology and the economy. Maybe even those marks are not being hit and we could pursue alternatives.

Mathematical activity is commonly understood as being targeted at evoking particular mathematical concepts. Alternatively, however, the activity could be understood as a microcosm of social activity more generally. Mathematical activities governed by certain procedures, rules, performance-criteria, etc. might be referenced to other social discourses, including others specifically related to mathematical heritage. Seen in this way, mathematical objects become a function of their relationship with multiple discourses. This softens any assumption that the activities are necessarily anchored in specific mathematical concepts. Rather, the reification of the supposed concepts is unfolded across multiple sites. Here, there would be no universal conceptions of what mathematics should be about; rather, our conceptions would be linked to the historical and social processes that generated classroom mathematics in the material forms it now takes. As suggested, the advance of mathematical thinking is defined by the production of objects, often in response to newly defined applications, funding priorities and pedagogical circumstances, or as a result of ever more pervasive formal assessment demands in schools. 
Such trends are consequential to school mathematics being pulled in two directions at the same time. School mathematics serves mathematical heritage, and often mathematics education research understands its task in terms of serving that ambition. This orientation however obscures the demands of a more insistent master to be found in the political and economic structures that shape so many of our everyday actions, and in particular our encounters with what mathematics has become in Anglophone contexts at least (Brown, Hodson \& Smith, 2013). The pursuit of economic ambitions sometimes seems to result in school mathematics favouring the performance of skills and procedures rather than nurturing the student's more intuitive powers of mathematical rationality. Contemporary politics, however, is complicated by the disjunction of governmental politics and the operation of the market, which forces the hand of state to adopt certain forms of economic policy (Bauman, 2014). That is, real power is no longer with governments setting policies, and the explicitly stated regulative apparatus that shapes school practice reveals that governments are merely acting in the service of oligarchic powers that transcend them, and over which they have little control in terms of delivering an equitable distribution of economic, cultural and educational capital (Piketty 2014). Pais (2015) takes the example of how motivation is activated between the two contrary demands and transcends much work on beliefs in mathematics education research by insisting on an over-arching political dimension in linking mathematics to beliefs about what it is:

(To) believe that mathematics as an object has already in itself the properties that will trigger students' desire for learning is to neglect all the students for whom engagement in mathematics does not derive from a 'will to learn' but from a will to satisfy some Other's demand (say, parents' demand for good grades, teachers' demand for learning, academic or professional demands, etc.). It is an aspiration as pious as it is naive to assume that students will engage in mathematics for the satisfaction of exploring mathematics. To use the Lacanian lexicon, it is the cause and not the object of desire that determines students' engagement in mathematics. This cause has to be located not in intrinsic characteristics of mathematics nor in the innermost core of student's being, but in politics.

The mathematics that we encounter in schools has been shaped according to ideological schema to produce its pedagogical forms, schematic applications and the type of students it wants to include or exclude, or can afford to fund or not. The assessment of school mathematics, for instance, is linked to the regulation of citizens as part of what Althusser, (1971) sees as the wider ideological state apparatus "through which the symbolic machine of ideology is "internalised" (Žižek, 1989, p. 43). Ideology speaks through us by processing what we say according to its preferred mode of shaping the world. It "is language that uses us" (Lacan, 2007, p. 66). But for Lacan, the representations, or actuality, of school mathematics evoke rather than fully capture more embedded or historical mathematical understandings. That mathematics is supposed to be slightly beyond reach gives it a mystery and allure. For the advanced mathematician, the attraction may be the supposed abstraction that transcends the mere symbols. For the less enthusiastic student, it may be cool not to be a geek. The name "mathematics" is a "pure signifier that designates, and at the same time constitutes its identity" and "locates something that is beyond the variable cluster of its descriptive properties" (Žižek, 1989, p. 98) thwarting a consistent ideal account of what mathematics "is". Peeling away all of the layers leaves us with nothing. There "is no 'world' outside language, no world whose horizon of meaning 
is not determined by a symbolic order" (Žižek, 2012, p. 366). As Lacan (2007, p. 124) puts it: "language ... cannot be anything other than a demand, a demand that fails". Mathematics is only produced through activities taking place in its name, but this name has been linked to particular political preferences that do not reveal their true purpose.

\section{The point of my own teaching}

So what are we pointing at when we are pointing at mathematical entities, a layer of an onion, an inner kernel? The paper proposes to argue that mathematical entities comprise the very play of perspectives on them. Here, I will describe some work that I have done with some students where I have explored these issues from my perspective as a teacher. I have a regular weekly class with a group of adults, typically in their twenties and thirties, from a range of professions, retraining to be mathematics teachers in British secondary schools. As non-mathematics specialists, they are offered the opportunity to develop their pedagogical understanding of mathematics over a period of 6-9 months prior to entering the year long, school-based postgraduate "training" course now typical in England and Wales. My ambition as their teacher is to introduce them to a broad range of mathematical experiences over 20 3-hour sessions prior to the intensity of the subsequent training year where a relatively reductive version of school mathematics will be encountered. Brown, Rowley, and Smith (2015) have discussed how this model of training compresses both teacher subject knowledge and the teacher's understanding of her own professional challenge.

In some activities directed towards enabling the students to develop their spatial awareness as a prelude to a more formalised approach to geometry, they were invited to explore various body movement activities. My intention here was to explore geometric entities from multiple perspectives, especially from inside very large versions of these configurations. For example, a student was asked to position herself between two dots on the ground that were about four metres apart, but where she was twice as far from one dot as she was from the other. She was asked to walk so that she was always twice as far from one dot as she was from the other. Alternative interpretations were provided as various students attempted this challenge. My hope was that there would be a lot of variety in the responses so that alternative ways of making sense of the situation could be shared and compared later. A number of students produced drawings linking the points that satisfied the conditions, showing that they made a circular path (Fig. 1):

Another student reported a completely different experience in connection with the same problem. His response was to produce the following set of equations, seeing the same circular loci but in algebraic terms:

$$
\begin{aligned}
& (x-12)^{2}+(y-0)^{2}=6^{2} \\
& x^{2}-24 x+144^{+} y^{2}=36 \\
& x^{2}-24 x+108^{+} y^{2}=0
\end{aligned}
$$

I checked that the formula is correct by solving when $y=0$.

$$
x^{2}-24 x+108=0, x=6 \text { or } 18 .
$$

The issues became yet more complicated as the problem shifted to remaining twice as far from one dot as from the other in three-dimensional space. The challenge provoked much 

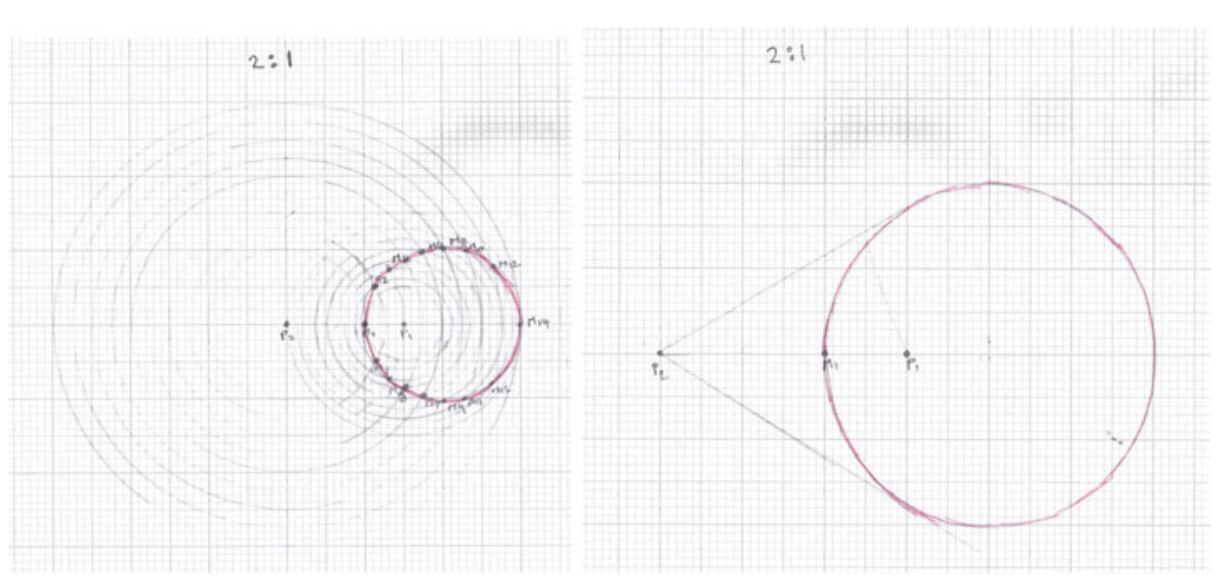

Fig. 1 Constructions of circles

ostensive gesturing alluding to points beyond immediate grasp and constructions out of string to confirm speculations (see Fig. 2).

This experience was written up at home as part of a diary package that would eventually be submitted for the course assessment. The course is set up at the outset as a place where we all research on how people learn mathematics. Starting with ourselves and our own learning, we tell stories of our experiences towards building some sensitivity to understanding how similar situations can be experienced in very different ways and that our own learning can be enhanced by trying to see my problem through someone else's eyes. We explore our respective beliefs and expound the rationalities that link them. For example, two students in the same subgroup experiencing the same discussion documented the different ways in which they saw their colleagues had made sense of the problem:

people do not visualise the same problem in the same way ... each individual gave very different, but equally valid, explanations ... for seeing a circle in 3D ...: a penny being spun around at the end of a piece of string; modelling the shape with your hands; imagining being the origin of the circle (therefore being inside the shape) and what it

Fig. 2 "Conceptualising" a threedimensional object using string

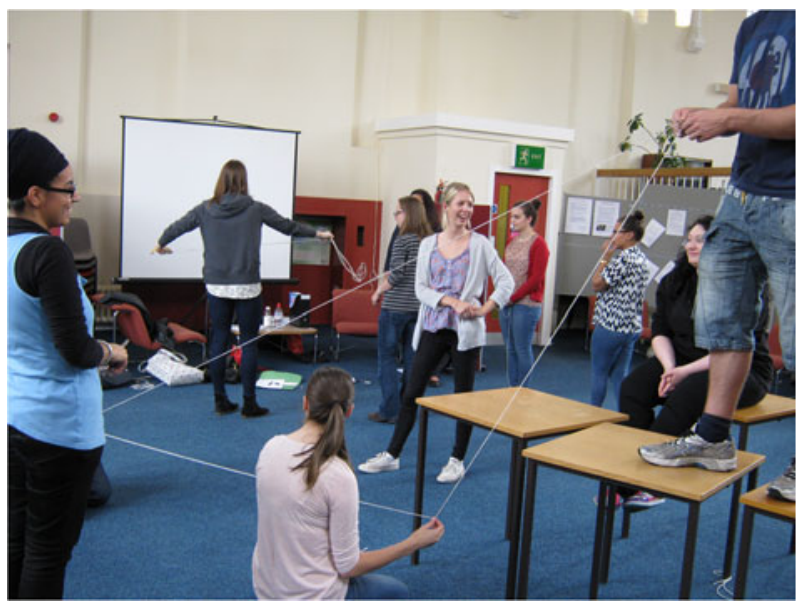


would look like looking in each direction; imagining the shape being built up from the established points which were on the ground.

This student produced a drawing to show her own image (See Fig. 3).

What was interesting was the different ways in which we described our thoughts and showed them to the group. $\mathrm{N}$ was thinking and demonstrating as if she was inside the shape. S looked like she was thinking outside the shape. I thought of the shape spinning on a fixed axis, this fixed axis being along the line of the 2 fixed points I was also visualising the shape on a $3 \mathrm{D}$ type computer programme. $\mathrm{J}$ thought of it spinning on a fixed axis and used the idea of spinning of a coin to explain. We all agreed that the shape made would be a sphere.

This second student continues:

Even though we all had different conceptualisations of what the curve looked like in 3D we could agree that we were talking about the same curve. This happened because each individual explained their visualisation and it fitted in with each of the other individuals conceptualisation. For example, I imagined looking at the shape from the side seeing the established points and building it up from there. However I could see that the image of a penny being spun fitted with my visualisation so could assume that person was having an equivalent (and yet different) visualisation to me.

So, a sphere is a sphere but different people can experience it in different ways at different times (as a set of equations, drawing, as an imagined ostensible object, like this ball). "Every interpretation is partial, 'embedded' in an interpreter's ultimately contingent subjective position” (Žižek, 2012, p. 359). Qualitative or perspectival dimensions supplement the mere fact of a sphere. Observing and making sense of the experience of others can further develop the qualitative or subjective experience of the sphere. For some, there was a revelation in realising that the sphere could be understood or approached in many different ways, and that the equivalence of these alternative approaches might be demonstrated. As their teacher, I opened many opportunities for ideas to be negotiated or exchanged. The students typically worked in small groups but regularly came together for whole class discussions. Every half an hour, I typically stopped the group so that they could engage in $5 \mathrm{~min}$ of private reflective writing to capture as "live data" how their understandings were developing. On some

Fig. 3 A sphere

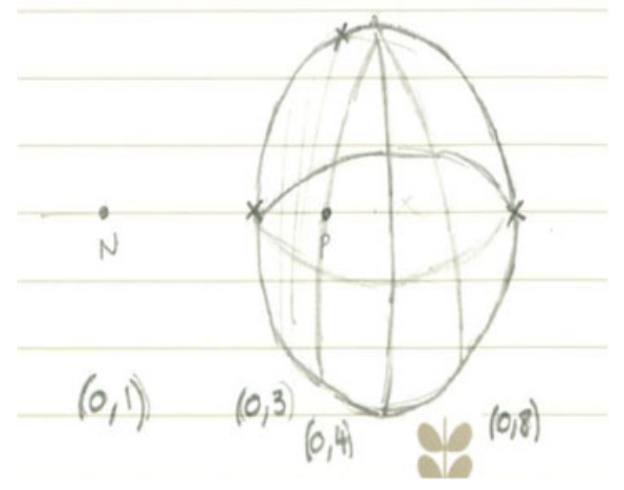


occasions, students were invited to read their comments aloud with view to revealing the diversity of response. For their "homework" after the session, students were urged to build a commentary of the lesson out of these pieces of reflective writing combined with their written mathematical work. The story of "how the learning took place" for the individual and for the different subgroups was emphasised as a major lesson objective. That is, the pedagogical story was valued as well as the mathematical story in the steep learning curve entailed in the student's journey from seeing mathematics primarily as subject knowledge, to seeing it as pedagogical content knowledge, or as mathematics conceived from the point of view of a learner. In a separate study, I worked with a colleague in enabling graduate student teachers of English to document their own personal changes in relation to their subject area over a year as a key dimension of their course assessment (Hanley \& Brown, 2015).

On the occasion described, another student reported a more affective experience of being within the activity:

On reflection, at that moment, I felt a real mix of emotions which combined many of the emotions that pupils face when asked to speak in class, in situations where they are not completely sure of what they are talking about. These involved almost a fear of saying the wrong thing, a desire to achieve the right answer, a wish not to appear foolish in front of the 'teacher' and peers and also a concern over whether my explanation will be understood or even make sense.

This extract suggests that her mathematical experience was imbued with social, emotional and historical baggage. The imagination of the object in question, however, has real effect on the person's image of his or her self in attempting to make the object that is being sought tangible. The person is reflexively constituted through their attempt to grasp it. The grasp reveals aspects of who they are. Thus, the activity as a whole was centred on each student exploring alternative subjective positions, on documenting connections to alternative formations of self such as a physical self moving in space, a pedagogical self reflecting on the learning of others, a geometric self creating drawings, an algebraic self solving formulae and an emotional self commenting on how it felt relating to other students in the context of the supposed mathematical entities. But in building these images of oneself, one is alerted to territory that one can grasp in a tangible way and seemingly to spaces beyond reach that can only be pointed to or speculated. There are questions as to from where things are being seen. What am I seeing? Who, when or where am I precisely to be seeing it in that way? What had been movements of the body became elements of one's comprehension of reality itself. The experience of the configurations became linked to how one felt at the time, a narrative of participation formalised for posterity, seemingly held in place by both rationality and belief at "the moment of pure subjective decision or choice which stabilizes a world” (Žižek, 2012, p. 367).

Each time, these sessions are new for me in my role as the teacher as each individual account has unique features and a particular storytelling style. This year, the sessions have been enlivened by a move to a large brand-new building that allows new spatial experiences - a huge internal atrium for suspending/stretching string in $3 \mathrm{D}$, a drama studio that allows spotlighting, expansive flat space outside (where cold weather tempered the pleasure of making the curves very large), etc. My persistent ambition, the point of my teaching spelt out for my students, is for me to see things in new ways, to keep my teaching alive by enabling my students to provide new stimulus to each other and to me, to resist final versions that sum things up, towards recognising and perhaps specifying the limits of one's certainties and uncertainties. 


\section{Rationality and belief}

We process reality by referencing our experiences to our preferred ways of telling our stories. Žižek's favourite example is the cinema since it provides us with the story forms against which we can gauge the pleasures and disappointments of our own everyday lives. We could as easily see schooling as a similar arena in which we make sense of who we are. The rationality of school mathematics might be seen as being contingent on how we prioritise and order the ostensible objects that we believe to be a part of it within the school setting. We recognise ourselves in the stories we tell, but not quite, and our attempts to get a better fit motivate our participation. Any apprehension of reality requires a subjectively located view to structure what we see. We need to ask where are we coming from in seeing things in the way that we do. And ultimately, our assumptions as to where we are coming from become part of reality.

The retroactive twists we make on our narratives of participation, and our attempts to stabilise them in some way for posterity, comprise the very production of reality. The lived experience of a sphere is condensed into a form of words, a set of symbols, some drawings or the articulation of a mixed set of emotions. The mimetic act of making sense through experience produces reality in the always already failed attempt to stabilise the world to scrutinise it. The attempted conflation of time produces a parallactic play of perspectives, a compression of points of view, which necessarily exceed my sense of self achieved in any singular perspective.

So then, are we pointing at mathematical objects in which we believe as a consequence of our empirical experience or do we know that they are there as a result of rationally thinking them into being consequential to making sense of that experience? The controversial British scientist Richard Dawkins (2006) has provoked much public debate as a result of seeing scientific rationality and religious belief as being in opposing camps: "I am against religion because it teaches us to be satisfied with not understanding the world". ${ }^{3}$ Yet, reason and belief are not simply opposed to each other. A hermeneutic circularity is implied where beliefs produce rationality and vice versa. More radically, from a Hegelian perspective, "the object is always-already bound up in the complex mediating process of the subject's thinking it, and conversely, the subject's thinking the object is itself bound up in the object's very existence" (Davis, 2009, p. 14). "What we experience as reality is not the thing itself, it is always-already symbolised, constituted, structured by way of symbolic mechanisms" (Žižek, 2011, p. 240).

Sverker Lundin brought my own production of reality to my attention after reading an earlier draft of this paper. Sverker asked whether I, Tony Brown, as I understand myself, ultimately believed that there is a field of mathematics beyond all of the ideological distortions. Such a belief appeared to be materialised in my mode of expression, perhaps through an overcasual use of words by force of habit, as if I had left some part of mathematics undisturbed by the ideological analysis, and then discussed distortions, desires, relationships, positions, etc. If this were to be the case, Lundin suggested, mathematical objects would be analysed:

as nothing more than reifications of discursive practice - as the result of 'counting as one' a range of practices, the result of geographical invariance and chronological stability, the result of learning to relate to them as objects, etc.

\footnotetext{
${ }^{3}$ Source Google. Dawkins was the University of Oxford's Professor for Public Understanding of Science from 1995 to 2008 (Wikipedia).
} 
Yes, I am guilty as charged as I still am quite unable to exorcise past versions of self, which have made me the fully consistent academic who I am now. A Lacanian account of the human subject has no aspiration to settle down with a final correct version.

Lundin convincingly prefers to assert an alternative view that allows for temporal adjustment and qualitative shifts of perspective, which requires one:

to analyse the seeming impossibility of this first step as an ideological effect - that is: to understand the seeming obviousness of there being something 'more' in mathematics, beyond politics, economy, schooling, as the sublime of mathematics, as something that is already part of step one, as a necessary part of the constitution of the objectivity of mathematics as such.

Here, we do not have a mathematical backdrop that gets distorted through subsequent usage. This unity never existed in the first place. It "is just a retroactive illusion" (Žižek, 2014, pp. 49-50). Further: "nothing has been abstracted from any reality. On the contrary it's already inscribed in what functions as this reality" (p. 14). The reality of the pointing hand described in our first example is embraced by a symbolic universe, which is disturbed by its inclusion, whether it is seen as a "random gesture" or it has a "clear purpose".

Mathematical thought derives from realities that are consequential to past human endeavours or conceptualizations. Many mathematical objects have an empirically motivated dimension; circles are motivated by naturally occurring phenomena, iterative processes model human experience of progressively getting closer, statistics organises clusters of human information, etc. But often, this empirical motivation underlying mathematical forms is lost in history, and we may not fully appreciate the implications of earlier empirical motivation for structuring our thoughts in particular ways and how they now influence our preferred or familiar ways of making sense. We also lose track of how past ideological/subjective perspectives are built into current ways of looking. For example, the concept of sphere may influence the way in which we mark out space. Indeed, is direct apprehension possible without historically derived markers (that bring with them their own past ideological priorities or contingent intuitive sense of how things work)? Or might we need to loosen our reliance on past structures (e.g., Newtonian physics) and experience space through alternative constructions (e.g. relativity in space, sub-aqua spatial dynamics, quantum physics).

We reflect the symbolic universe, and it reflects us. Both Darwin and Einstein were great individual figures, but the novelist Ian McEwan (2012) in his Guardian article "The originality of the species" argued that they were each standing in evolving symbolic universes at particular moments in time that would deliver the results to someone or other in due course. ${ }^{4}$ Ultimately, like Hawking or Dawkins, they have become iconic figures providing symbolic points of reference and particular inflections that seek to stabilise ever-shifting discursive arrangements. They successfully "cut" reality into a particular time-dependent configuration that allowed a particular kind of subjective hold or brought a particular form of "master-ized" discourse into play (Lacan, 2007, p. 103). which is a style of discourse picked up by others that shapes the character of the field and privileges some points of view over others.

School mathematics and other types of mathematical activity are built in the human's own self image as they reflect the human challenges for which they are created. Humans, however,

\footnotetext{
${ }^{4}$ Darwin was ultimately fitter than Alfred Wallace who simultaneously reached the same conclusions independently, and so it was Darwin who was naturally selected and survived! See: http://www.bbc.co.uk/news/ukwales-21549079. Due respect goes to the referee who was unconvinced by this example.
} 
are also a product of the worlds that they have produced, where a division of labour has arisen to reflect and serve the prevailing social administration. The mathematical entities that they have constructed are then built into the human self-image as they reference themselves to the world that they have created. A child may understand herself in terms of her shoe size, the number of dolls she has, her age or her math scores. A teacher may understand himself in terms of his key performance indicators, tax rate, postcode or Prozac dosage. These parallactic self-producing and self-validating rationalities trap us into believing that there are universal realities (or rationalities) as to what it is to be mathematical and as to what it is to be human. What had been understandings of ourselves have become policing structures. Mathematical thought presented as a set of potential acquisitions has created the belief that there is something more tangible that assumes the quality of reality. Rationalities are then produced that are particular to those contingent arrangements or understandings of the world. The material points of reference that characterise school mathematics then support both a belief in mathematical entities referenced to contemporary societal structures and a contingent rationality that connects them. Rational mathematical thought necessarily rests on beliefs set within a play of ideological framings that sort people into types by limiting mathematical and pedagogical options. School mathematics then, built in a contemporary human self-image, presents not so much a distortion of "genuine" mathematical thought as a particular mode of thinking that serves to produce then select learners according to arbitrary curriculum and assessment criteria.

In brief, mathematical productivity results from a play of ideological perspectives, where arbitrary perspectives are selected to facilitate social administration, but in so doing reduce mathematics by restricting the sorts of more personal insights that can be acknowledged in a school setting. I have sought to show through my own teaching how mathematical challenges might be seen more in terms of students being supported in developing accounts of and gaining confidence in their own perspectives rather than meeting preset objectives. The challenge to the reader that this paper advocates is to loosen this administrative grip through his or her own preferred point of leverage (ballot box, adjusting teaching style, influencing curriculum decisions, political resistance, writing a paper for ESM, etc.) to allow individuals to release their own powers to generate diversity in their mathematical understandings rather than conformity.

Acknowledgments This paper was first presented at the second Manchester conference on Mathematics Education and Contemporary Theory. Papers from the two conferences have appeared as special issues of this journal. The third conference is scheduled to take place in July 2016. This paper comprises a further staging post in an ongoing discussion. Sverker Lundin, Julian Williams and Alexandre Pais each provided excellent critical responses to earlier drafts and lived to tell the tale. I would also like to thank Sarah Harrison, Christina Livingston and Sue O'Neil for their contributions to this paper. Jo Kennedy took the photo. But thanks mostly to Liz de Freitas and to Alex Pais for coming from places afar to live and work in Manchester.

\section{References}

Althusser, L. (1971). Ideology and ideological state apparatuses. In B. Brewster (Ed.), Lenin and philosophy and other essays (pp. 127-186). London: New Left Books.

Barad, K. (2007). Meeting the universe halfway: Quantum physics and the entanglement of matter and meaning. Durham: Duke University Press.

Bauman, Z. (2014). Lecture at Politics in times of anxiety conference. Manchester University, 9th June.

Brown, T. (2011). Mathematics education and subjectivity: Cultures and cultural renewal. Dordrecht: Springer. Brown, T., \& Clarke, D. (2013). Institutional contexts for research in mathematics education. In M. A. Clements, A. Bishop, C. Keitel, J. Kilpatrick, \& F. Leung (Eds.), Third international handbook of mathematics education (pp. 459-484). Dordrecht: Springer. 
Brown, T., Heywood, D., Solomon, Y., \& Zagorianakos, A. (2013). Experiencing the space we share. ZDM The International Journal of Mathematics Education, 45, 561-572.

Brown, T., Hodson, E., \& Smith, K. (2013). TIMSS mathematics has changed real mathematics forever. For the Learning of Mathematics, 33(2), 38-43.

Brown, T., \& McNamara, O. (2011). Becoming a mathematics teacher: Identity and identifications. Dordrecht: Springer.

Brown, T., Rowley, H., \& Smith, K. (2015). Sliding subject positions: Knowledge and teacher educators. British Educational Research Journal. Advance online publication. doi:10.1002/berj.3203.

Davis, C. (2009). Introduction: Holy Saturday or resurrection Sunday? Staging an unlikely alliance. In C. Davis, S. Žižek \& J. Millbank (Eds.), The monstrosity of Christ: Paradox or dialectic? (pp. 2-23). Cambridge, MA: The MIT Press.

Dawkins, R. (2006). The God delusion. London: Bantam.

De Freitas, E., \& Sinclair, N. (2012). Diagram, gesture, agency: Theorizing embodiment in the mathematics classroom. Educational Studies in Mathematics, 80(1-2), 133-152.

De Freitas, E., \& Sinclair, N. (2014). Mathematics and the body: Material entanglements in the classroom. New York: Cambridge University Press.

Derrida, J. (1994). The Specters of Marx: The state of the debt, the work of mourning, and the new international. London: Routledge.

Ernest, P. (2015) The problem of certainty in mathematics, Educational Studies in Mathematics. Advance online publication. doi:10.1007/s10649-015-9651-x.

Fischbein, E. (1987). Intuition in science and mathematics. An educational approach. Dordrecht: Kluwer Academic Publishers.

Goldin, G., Rösken, B., \& Törner, G. (2009). Beliefs - no longer a hidden variable in mathematical teaching and learning processes. In J. Maaß \& W. Schlöglmann (Eds.), Beliefs and attitudes in mathematics education: New research results (pp. 1-18). Rotterdam: Sense.

Hanley, C., \& Brown, T. (2015) Shifting subject knowledge identifications for student teachers of English, Journal of Curriculum Studies, in press

Lacan, J. (2000). Psychoses: The seminar of Jacques Lacan. Book III. London: Routledge.

Lacan, J. (2007). The other side of psychoanalysis: The seminar of Jacques Lacan: Book XVII. London: Norton.

Leder, G. C., Pehkonen, E., \& Törner, G. (2002). Beliefs: A hidden variable in mathematics education? Dordrecht: Kluwer Academic Publishers.

Mason, J. (1994). Researching from the inside in mathematics education: Locating an I-you relationship. Proceedings of the eighteenth conference of the group on the Psychology of Mathematics Education, (Vol. 1, pp. 176-194). University of Lisbon: PME. Extended version: Centre for Mathematics Education, Open University, Milton Keynes.

McEwan, I. (2012, March 23). The originality of the species, Guardian. Retrieved from http://www.theguardian. com/books/2012/mar/23/originality-of-species-ian-mcewan.

Pais, A. (2015). Symbolising the real of mathematics education. Educational Studies in Mathematics, 89(1). Advance online publication. doi:10.1007/s10649-015-9602-6.

Paton, G. (2012, March 2). Numeracy campaign: 17m adults 'struggle with primary school maths'. The Telegraph. Retrieved from http://www.telegraph.co.uk/education/maths-reform/9115665/NumeracyCampaign-17m-adults-struggle-with-primary-school-maths.html.

Piketty, T. (2014). Capital in the twenty-first century. London: Harvard University Press.

Roth, W.-M. (2012). Societal mediation of mathematical cognition and learning. Orbis Scholae, 6(2), 7-22.

Roth, W.-M., \& Radford, L. (2011). A cultural-historical perspective on mathematics teaching and learning. Rotterdam: Sense.

Skott, J. (2014). Towards a participatory approach to beliefs in mathematics education. In B. Pepin \& B. Roesken-Winter (Eds.), From beliefs to dynamic affect systems in mathematics education (pp. 3-23). Springer.

Williams, J. (2015). Alienation in mathematics education: Critique and development of neo-Vygotskian perspectives. Educational Studies in Mathematics. Advance online publication. doi:10.1007/s10649-015-9659-2.

Žižek, S. (1989). The sublime object of ideology. London: Verso.

Žižek, S. (2001). Did somebody say totalitarianism? London: Verso.

Žižek, S. (2006). How to read Lacan. London: Granta.

Žižek, S. (2011). The spectre of ideology. In I. Szeman \& T. Kaposy (Eds.), Cultural theory: An anthology (pp. 228-244). Chichester: Wiley-Blackwell.

Žižek, S. (2012). Less than nothing: Hegel and the shadow of dialectical materialism. London: Verso.

Žižek, S. (2014). Event. London: Penguin. 